\title{
BMJ Open Injury Prevention and long-term Outcomes following Trauma - the IPOT project: a protocol for prospective nationwide registry-based studies in Norway
}

\begin{tabular}{l}
\hline Jo Steinson Stenehjem (D) , ${ }^{1,2,3}$ Olav Røise (D) ,,5,6 Trond Nordseth, ${ }^{1,7,8}$ \\
Thomas Clausen, ${ }^{9}$ Bård Natvig, ${ }^{10}$ Svetlana O Skurtveit, ${ }^{9,11}$ Torsten Eken (1) ,6,12 \\
Thomas Kristiansen, ${ }^{6,12}$ Jon Michael Gran, ${ }^{2}$ Leiv Arne Rosseland ${ }^{1,6}$
\end{tabular}

\section{ABSTRACT}

Introduction Traumatic injuries constitute a major cause of mortality and morbidity. Still, the public health burden of trauma in Norway has not been characterised using nationwide registry data. More knowledge is warranted on trauma risk factors and the long-term outcomes following trauma. The Injury Prevention and long-term Outcomes following Trauma project will establish a comprehensive research database. The Norwegian National Trauma Registry (NTR) will be merged with several data sources to pursue the following three main research topics: (1) the public health burden of trauma to society (eg, excess mortality and disability-adjusted life-years (DALYs)), (2) trauma aetiology (eg, socioeconomic factors, comorbidity and drug use) and (3) trauma survivorship (eg, survival, drug use, use of welfare benefits, work ability, education and income).

Methods and analysis The NTR ( $n \approx 27000$ trauma patients, 2015-2018) will be coupled with the data from Statistics Norway, the Norwegian Patient Registry, the Cause of Death Registry, the Registry of Primary Health Care and the Norwegian Prescription Database. To quantify the public health burden, DALYs will be calculated from the NTR. To address trauma aetiology, we will conduct nested case-control studies with 10 trauma-free controls (drawn from the National Population Register) matched to each trauma case on birth year, sex and index date. Conditional logistic regression models will be used to estimate trauma risk according to relevant exposures. To address trauma survivorship, we will use cohort and matched cohort designs and time-to-event analyses to examine various post-trauma outcomes.

Ethics and dissemination The project is approved by the Regional Committee for Medical Research Ethics. The project's data protection impact assessment is approved by the data protection officer. Results will be disseminated to patients, in peer-reviewed journals, at conferences and in the media.

\section{INTRODUCTION}

Rationale for the study and scientific evidence gaps

The high volume of disability and symptoms after accidental trauma represent a significant

\section{Strengths and limitations of this study}

- Linkage of independent, national registries and data sources by use of a unique personal identification number for a comprehensive research database and complete control of loss to follow-up.

- Data from a number of nationwide registries enable a wide range of research questions within three main thematic areas: (1) public health burden, (2) aetiology and (3) survivorship.

- Approximately 27000 trauma cases from a highquality population-based trauma registry relying on mandatory reporting of incident trauma.

- Limited follow-up period (2015-2020) will hamper the analysis of some long-term outcomes, although a future extended follow-up has been planned.

- No blood samples, precluding the examination of molecular hypotheses.

burden and costs to individuals and society. ${ }^{1}$ Accounting for a total of 57.2 million years lived with disability on a global scale in $2017,{ }^{1}$ traumatic injuries constitute one of the major causes of mortality and morbidity in our society. Still, the public health burden of trauma in terms of descriptive statistics of trauma incidence rates, excess mortality from other causes of death than trauma and disability-adjusted life-years (DALYs) have not been well characterised by the use of national trauma registry data. ${ }^{2}$ The DALY measure was developed in the Global Burden of Disease project, ${ }^{34}$ and describes the gap between the current disease/injury situation and an ideal situation where lives are lived without the disease/injury in question.

Although many injuries are preventable and some effective prophylactic strategies have been established, the potential for 
improvement is still high. Demographic factors such as low socioeconomic status have been identified as independent risk factors of accidental trauma in young drivers and for trauma occurring at the workplace. ${ }^{5-7}$ Another important risk factor for trauma is occupation, where 'first-responder' occupations (ie, police, ambulance and fire fighters), fishermen and miners have been reported to be at increased risk of traumatic work-related injuries and fatalities. ${ }^{8-11}$ Comorbid conditions such as diabetes, insomnia and attention-deficit hyperactivity disorder have been associated with increased risk of traumatic injuries, ${ }^{12-14}$ and there is a need of further registrybased research to identify other possible patient groups susceptible to increased trauma risk. Also, alcohol, illicit or prescribed opioids and other psychoactive drugs are known risk factors of road traffic accidents, falls, and interpersonal violence, and thereby traumatic injuries. ${ }^{15-18}$ Therefore, a broad approach to examine the aetiology of traumatic injuries with population-based data is warranted. Better insights into the possible aetiologic role of demographic factors, occupation, comorbidity and drug use may enhance prevention strategies and thereby reduce the burden of trauma to society.

Use of population-based registry data also provides a unique possibility to gain new insights into trauma survivorship. Associations between posthospital trauma treatment and long-term outcomes such as drug use, mental health, work ability, education and ultimately survival have not been well-studied with population-based data. ${ }^{19-26}$ Opioids are commonly administered to survivors of major trauma and represent a cornerstone in acute pain management during a hospital stay. Chronic pain after hospital discharge is optimally treated with non-opioid drugs. However, opioid prescription has recently been increasing in patients with chronic pain, ${ }^{24}$ and use of opioids among trauma patients after hospital discharge has not been sufficiently described with population-based registry data. ${ }^{27-33}$ Another important research topic in the field of trauma survivorship is mental health following accidental trauma. Mental illness, such as post-traumatic stress disorder (PTSD), is estimated to occur in one of six trauma victims, ${ }^{33}$ but most surveys cannot address this accurately because the assessment of lifetime PTSD might be affected by the respondents' condition at the time of reporting. Therefore, registry data containing physiciandiagnosed mental disorders are warranted to objectively assess the burden of mental illness, and its predictors, in trauma survivors. Some population-based studies have reported on long-term work ability following trauma, ${ }^{2634-36}$ and found that patients with severe trauma are more likely to receive social benefits and have a delayed return to work compared with minor or moderate injuries, ${ }^{26}$ and that age, type of work and receiving compensation are important predictors for post-trauma work ability. ${ }^{34} 3637$ Overgaard et al reported an overall survival of $78 \%$ after 7.3 years (median) of follow-up of 322 Danish trauma patients, and that they had a lower health-related quality of life compared with healthy controls. ${ }^{38}$ Still, there are few nationwide and large-scale studies with long-term follow-up data of work ability and education in trauma survivors.

Data from the Norwegian National Trauma Registry (NTR) has been available for research purposes since 1 January 2015, but no previous study has addressed the epidemiology of trauma in Norway using nationwide data. As pointed out by Uleberg et $a l,{ }^{26}$ a description of the overall consequences of trauma for a given population should ideally include all injured patients within a geographical area, within a specified time interval and with complete data capture for follow-up. By establishing the IPOT project, we seek to fulfil these requirements by establishing a comprehensive research database based on the NTR coupled with the data from several sources. This will enable research on areas in traumatology where it is well-documented that acquisition of new knowledge is crucial for reducing a major public health problem.

\section{Aims and research questions (RQs)}

The overall purpose of the IPOT project is to provide insights into multiple aspects of traumatology. By comparing a complete national trauma population with healthy controls over the course of preinjury and postinjury follow-up, the project will enable research on the following: (1) the public health burden of trauma, (2) the aetiology of trauma and (3) trauma survivorship. More specific RQs for the present and ensuing studies to each thematic research area are delineated in table 1.

\section{METHODS AND ANALYSIS}

\section{Study population and data sources}

The Norwegian trauma system

The Norwegian healthcare system is publicly funded and the first national plan for a nationwide trauma system was launched in $2007 .{ }^{40}$ In 2013, the Norwegian National Advisory Unit on Trauma was established, and led the revision of the national trauma plan to include all phases of trauma care by 2017 (eg, first aid, prehospital emergency medical services (EMS), hospital care and rehabilitation). The Norwegian trauma system comprises a geographically dispersed paramedic-manned ground ambulance service and a nationwide physician-manned helicopter EMS. There are 34 acute care trauma hospitals and four regional university hospitals with status as the trauma centre (ie, capable of definite care for all major injury) within each of Norway's four health regions. The regional trauma centres are equivalent to the level I or II trauma centres described by the American College of Surgeons Committee on Trauma. ${ }^{41}$

\section{The NTR}

The primary aim of the NTR is to monitor the quality of treatment given by the trauma hospitals in the national trauma system to facilitate continuous improvement of the trauma care chain in Norway. The NTR Scientific Council has a representative from each of the four regional health 
Table 1 Thematic research areas and research questions

\section{Public burden of trauma}

1.1 What are the incidence rates of trauma, by trauma type/severity, age, sex and year?

1.2 Description of trauma incidence and mortality rates during the time period 2015-2018

1.3 Is there an excess mortality of non-trauma deaths among trauma survivors compared with the general Norwegian population?

1.4 Description of DALY rates among trauma survivors over the time period 2015-2018

\section{Trauma aetiology}

What are the associations between trauma risk and the following:

2.1 Demographic factors, that is, age, sex, socioeconomic status, education, income, family situation, urban versus rural?

2.2 Occupation?

2.3 Comorbidity?

2.4 Drug prescription?

\section{Trauma survivorship}

3.1 Are trauma survivors at increased risk of the following outcomes compared with healthy controls:

\subsubsection{Long-term prescription of psychoactive drugs?}

3.1.2 Contracting mental illness and other noncommunicable diseases?

\subsubsection{Reduced work ability?}

\subsubsection{Death?}

3.2 To what extent is the quality of post-trauma treatment/ rehabilitation associated with increased risk of:

3.2.1 Prescription of psychoactive drugs?

3.2.2 Mental illness?

3.2.3 Reduced work ability?

3.2.4 Death?

DALY, disability-adjusted life-year.

trusts in Norway (south-east, west, central and north), representatives from the medical specialist associations (anaesthesiology, surgery, orthopaedic, neurosurgery, physical medicine and rehabilitation) and a user representative. Since 2015, all trauma-receiving hospitals admitting patients with severe injury or suspected severe injury have been required by the Ministry of Health to routinely include all those in the NTR, ensuring nationwide individual coverage of $>95 \%$ and about $98 \%$ completeness on the key variables. ${ }^{42}$ The registrars who collect and record data for the NTR are formally trained in injury coding according to the Abbreviated Injury Scale (AIS) 2005, update 2008. ${ }^{43}$ The NTR holds information on patient demographics, preinjury comorbidity, ${ }^{44}$ prehospital and in-hospital care as displayed in table $2 .{ }^{42}$ To secure valid comparisons of trauma registry data between countries,
Table 2 Variables extracted from the Norwegian National Trauma Registry

\section{Data type Variable name}

Demographics

Age

Sex

Treating hospitals

Preinjury comorbidity

Injury and prehospital care

Date and time of events

Geographic location

Mechanism of trauma

Physiologic status at scene

Glasgow Coma Scale score at scene

Injury descriptors (Abbreviated Injury Scale)

In-hospital care

Physiologic status at hospital arrival

Glasgow Coma Scale score at hospital arrival

Blood samples (incl. base excess)

Radiologic examinations

Emergency surgical interventions

Respiratory support

Length of stay ICU/hospital

Scores

Revised Trauma Score

Injury Severity Score (ISS)

New ISS

Glasgow Outcome Scale (discharge)

ICU, intensive care unit.

the core NTR dataset is based on the Utstein template for uniform reporting of data following major trauma. ${ }^{43}$

All injured patients who are alive when the prehospital personnel arrive at the scene of injury and who (1) have been met with trauma team activation on hospital arrival or (2) have been treated in a trauma-receiving hospital without being met by trauma team activation with New Injury Severity Score (NISS) $>12$ or with a single head injury of AIS $\geq 3$ are included in the NTR. Patients who are dead at scene when prehospital personnel arrive or patients who die on route from the scene of injury to the hospital are also included. The criteria for trauma team activation for the hospitals are similar and defined in the national trauma plan. ${ }^{40}$

Between 1 January 2015 and 31 December 2018, 33070 trauma records were registered in the NTR. As displayed in figure 1 , we performed the following exclusions to prepare the raw NTR data file for linkage with multiple data sources: missing AIS code $(n=2829$, eg, trauma alarm on suspected severe injury who was later discharged 


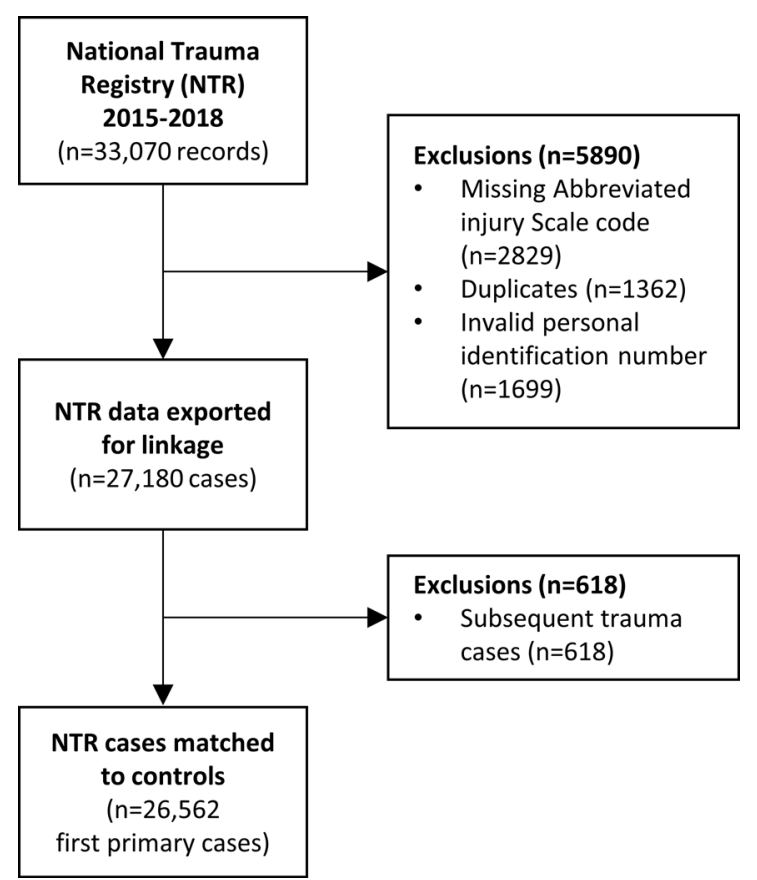

Figure 1 Overview of data flow and exclusions.

without any injury and hence no AIS code), duplicate records due to transfers $(n=1362$, eg, registrations at the same date) and invalid personal identification number ((PIN), n=1699, eg, non-Norwegian citizens who are assigned a pseudo-PIN for hospital-tracking purposes). After these exclusions, we were left with 27180 trauma cases of which 26562 were the first occurring trauma in each individual and 618 were subsequent traumas occurring later in the same individual.
Linking the NTR to the National Population Register for populationbased controls

Every resident in Norway is registered in the National Population Register with a unique 11-digit PIN. The NTR population of trauma cases will be matched to populationbased controls from the National Population Register. The controls thereby constitute a representative sample of the entire Norwegian population. After matching each trauma case to 10 controls, the nested case-control (NCC) study population will be merged to populationbased registries and data sources as displayed in figure 2 by use of the PIN.

Linking the NCC study population to registries and data sources To be able to study both the aetiology of trauma and secondary outcomes following a trauma diagnosis, the NCG study population will be linked to data sources for the time period 2014-2020. This will yield a follow-up for trauma between 2015 and 2018 ( $\leq 4$ years) and a follow-up for post-trauma outcomes between 2015 and 2020 ( $\leq 6$ years). Variable lists for each data source are provided as supplementary material (online supplemental tables S1-S5).

Linkage to Statistics Norway provides data on marital status, education, income, occupation and use of welfare services and benefits, such as sick leave, parental leave and retirement pension (online supplemental table S1). The Norwegian Patient Registry includes information on admission to hospitals, rehabilitation institutions and specialist healthcare including dates of admission and discharge, as well as a comorbidity index and all primary and secondary diagnoses (online supplemental table S2) ${ }^{45}$ Linkage to the KUHR database will provide data

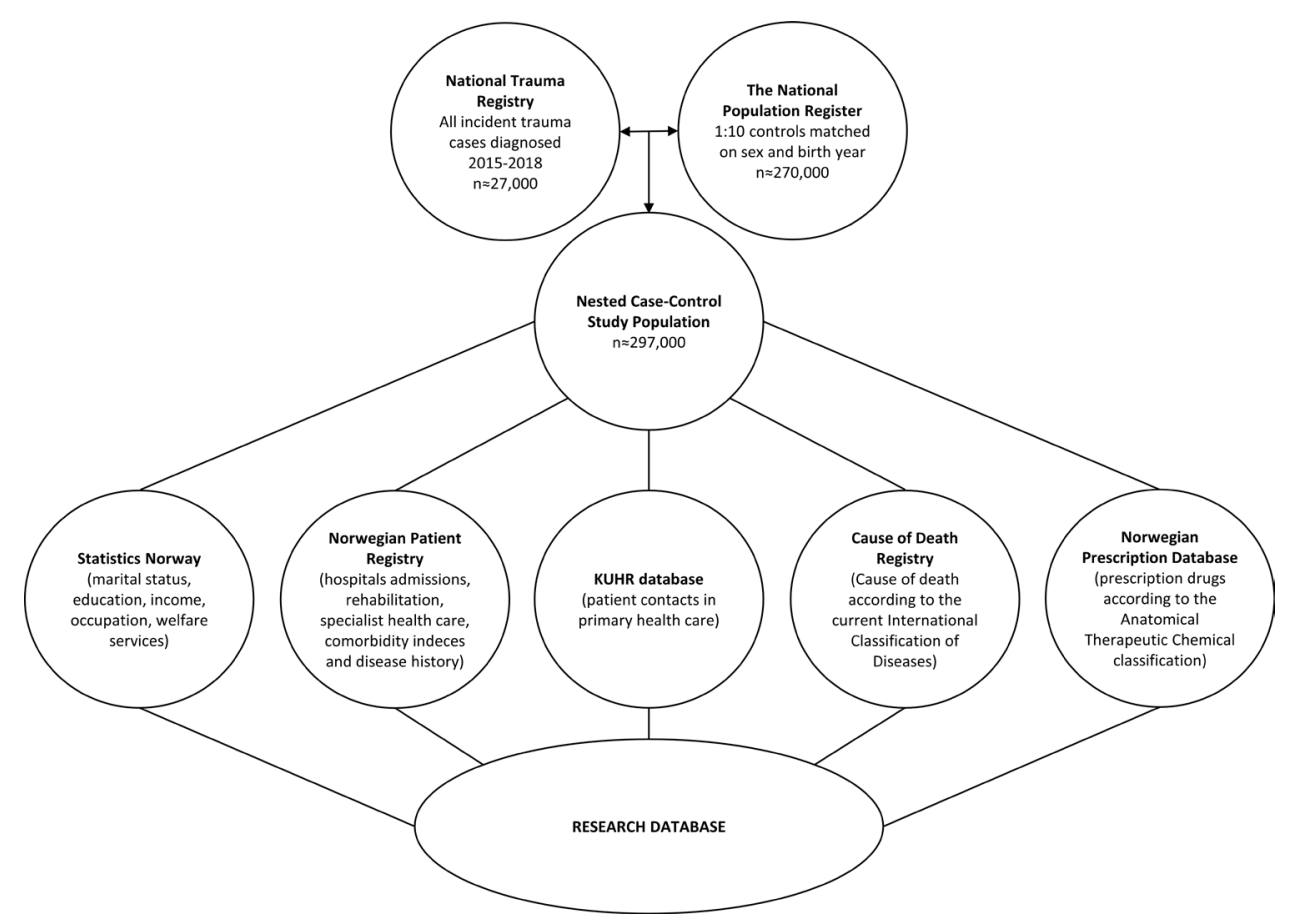

Figure 2 Overview of linkage between different data sources. 
on date/time and diagnoses from patient contacts with the primary healthcare service (eg, general practitioners, psychologists, physiotherapists and dentists; online supplemental table S3). The Cause of Death Registry provides the date and the cause of death according to the current International Classification of Diseases (online supplemental table S4). The Norwegian Prescription Database has since January 2004 held information on all prescription drugs dispensed to persons in ambulatory care, date of dispensing, amount dispensed (measured as Defined Daily Doses) and drug type according to the Anatomical Therapeutic Chemical classification system. ${ }^{46}$ Drugs with an increased risk of addiction (ie, opioids, benzodiazepines, z-hypnotics and other psychoactive drugs) will be given special consideration in the analyses (online supplemental table S5).

\section{Study designs}

Studies of the public health burden of trauma

The linkage of NTR data to the Cause of Death Registry and Statistics Norway offers excellent possibilities to address the public health burden that trauma poses on the Norwegian society. Using NTR data spanning 20152018, we will describe the trauma incidence by anatomic site and severity (AIS codes, ISS and NISS), age, sex and year (RQs 1.1 and 1.2) and in future studies, with NTR data covering a longer time period, also assess possible changes in incidence trends. Possible excess of nontrauma mortality may indicate underlying health problems among trauma survivors, and will be assessed by comparing the number of deaths among trauma survivors to background population mortality rates by computing standardised mortality ratios (SMRs; RQ 1.3). DALY is a suitable measure to quantify the burden of trauma in terms of 'healthy' years of life lost due to trauma, and whether this has changed over time (RQ 1.4).

\section{Studies of trauma aetiology}

Prospective case-control studies nested within the National Population Register will be carried out to study risk factors of trauma (RQs 2.1-2.4). In our setting where the National Population Register may be considered 'the cohort of Norway', the NCC design is more computational efficient and preferable over the regular cohort design as the latter would require inclusion of the complete National Population Register and thereby $>5$ million persons. Only 10 trauma-free controls are selected and matched to each case using an incidence-density sampling scheme. ${ }^{47}$ Also, the NCC design takes advantage of the prospective nature of the cohort study using data collected before any trauma diagnosis, and thereby reducing the potential for bias. A complete description of the case, control and matching criteria is given in table 3 .

\section{Studies of trauma survivorship}

The RQs concerning risk of secondary outcomes compared with healthy controls (RQs 3.1.1-3.1.4) will be addressed by a matched cohort design. ${ }^{48}$ The controls
Table 3 Overview of case, control and matching criteria for the nested case-control studies

\section{Case criteria}

\begin{tabular}{|c|c|}
\hline $\begin{array}{l}\text { No. of } \\
\text { cases }\end{array}$ & 26562 \\
\hline Verification & $\begin{array}{l}\text { Registered in the NTR by certified registrars } \\
\text { without missing AIS codes }\end{array}$ \\
\hline Definition & $\begin{array}{l}\text { First trauma case per individual registered in } \\
\text { the NTR 2015-2018 }\end{array}$ \\
\hline Selection & $\begin{array}{l}\text { First occurring trauma in each individual } \\
2015-2018\end{array}$ \\
\hline \multicolumn{2}{|c|}{ Control criteria } \\
\hline $\begin{array}{l}\text { No. of } \\
\text { controls }\end{array}$ & 10 per case \\
\hline Definition & $\begin{array}{l}\text { Alive, resident in Norway and no documented } \\
\text { trauma history before the case's diagnosis }\end{array}$ \\
\hline Selection & $\begin{array}{l}\text { Random sampling with replacement from pool } \\
\text { of available controls }\end{array}$ \\
\hline \multicolumn{2}{|c|}{ Matching criteria } \\
\hline Sex & Same sex as case \\
\hline Birth year & $\begin{array}{l}\text { Same birth year as case. Stepwise extension } \\
\text { by } \pm 1 \text { year, if necessary }\end{array}$ \\
\hline
\end{tabular}

AIS, Abbreviated Injury Scale; NTR, National Trauma Registry.

matched to each case for the NCC studies may be reused in a matched cohort design by considering the trauma diagnosis as an exposure. The aim will be to compare incidence rates of secondary diseases between trauma survivors and controls. For example, is the risk of mental illness higher among trauma survivors than healthy controls (RQ 3.1.2).

The RQs 3.2.1-3.2.4 will be addressed by applying analytic approaches as appropriate for a cohort study design. The 26562 persons registered in the NTR 20152018 will constitute the cohort of trauma patients. Posttrauma treatment and rehabilitation variables will be the main exposures of interest, and subsequent drug prescription (RQ 3.2.1), mental illness (RQ 3.2.2), reduced work ability (RQ 3.2.3) and ultimately death (RQ 3.2.4) will constitute the outcomes. For example, to estimate the effects of exposures such as timing/type of treatment after traumatic brain injury on future work ability (RQ 3.2.3.), we will focus on the best possible adjustment for important confounders (eg, sex, geolocation, type of injury, severity, occupation, income and education) using the data available in the comprehensive research database.

\section{Statistical methods and analyses}

Studies of the public health burden of trauma

Rates of trauma incidence and mortality will be agestandardised according to the WHO standard to facilitate comparisons between time periods and populations, ${ }^{49}$ and joinpoint regression will be used to assess possible changes in time trends (RQs 1.1 and 1.2).$^{50}$ 
To assess possible excess of non-trauma mortality among trauma survivors (RQ 1.3), SMRs will be calculated where the observed number of deaths among trauma survivors (numerator) will be compared with that expected (denominator) from background rates. The expected number of deaths will be calculated by multiplying the person-years generated by the trauma population (censored on the first occurring event of emigration, death or end of follow-up) with the sex-specific, agespecific (5 years) and period-specific (1 year) background rates.

DALYs will be calculated by adding years of life lost (YLL) to years lived as disabled or injured (YLD) according to the procedure described by Tainio et al. ${ }^{2}$ The YLL will be calculated by multiplying the number of deaths within strata of age and sex by the predicted life expectancy for the corresponding strata. The YLD will be calculated by multiplying the number of incident traumas with corresponding disability weights and estimated average injury duration for each trauma type. We will use the tables of life expectancy, disability weights and injury duration presented in Tainio et al. ${ }^{251}$

\section{Studies of trauma aetiology}

The statistical analyses of exposure-related trauma risk (RQs 2.1-2.4) will be performed based on matchedpair techniques, namely by applying conditional logistic regression where each case is matched to a specific set of controls. This approach will inherently adjust for sex and birth year (ie, same age at different calendar time points), as these variables are the matching variables. We will adjust for relevant possible confounders depending on the exposure in questions. For example, when studying opioids and other psychoactive drugs as risk factors for accidental trauma (RQ 2.4), we will adjust for comorbidity measured by the Charlson Comorbidity Index and the Norwegian Patient Registry Index. ${ }^{45} 52$

\section{Studies of trauma survivorship}

Comparisons of secondary outcomes among the trauma survivors with the general population will be addressed according to a matched cohort design (RQs 3.1.13.1.4) ${ }^{48}$ By adjusting for the matching variables from the NCC studies, we will be able to reuse the NCC controls in a matched cohort design. Cohort analysis of associations between post-trauma treatment/rehabilitation and risk of drug use, mental illness, reduced work ability and death/ poor survival among trauma survivors (RQ 3.2.1-3.2.4) will initially be assessed by a time-to-event analytic framework. Non-linear models such as restricted cubic splines will also be explored if a non-linear relationship between exposure and outcome is assumed. In the case of interaction effects, stratified results will be presented.

To appropriately analyse cause-specific survival and use detailed patient trajectories after trauma, we will consider competing risks and the use of multistate models as an extension of traditional time-to-event modelling. ${ }^{53}$ For models that aim beyond a mere predictive interpretation, we will make use of methods for causal inference. These include $^{1}$ the specification of well-defined target estimands with similar interpretation to those obtained in randomised trials, ${ }^{2}$ the use of graphical methods to aid identifying confounders and other potential sources of bias, and ${ }^{3}$ identification of target estimands, possibly based on recent methods addressing various advanced confounding problems in observational studies. ${ }^{54}$

\section{Power and sample size considerations}

The proposed NCC and matched cohort studies will include the whole NTR 2015-2018 yielding 26562 trauma cases and ca 265620 controls. The power to calculate an association between exposures in RQs 2.1-2.4 (eg, demographic factors, occupation, comorbidity and drug prescription) and trauma risk will depend on the following: (1) the number of trauma cases (and controls) available for a specific trauma type, (2) the proportion of cases and controls that are exposed to the factor in question and (3) the effect size for this particular combination of exposure and trauma type.

For the NCC studies, we did not have a priori knowledge about the proportions of cases and controls exposed to the factors in question (RQs 2.1-2.2). For the matched cohort and cohort studies (RQs 3.1.1-3.2.4), we neither had information about the proportions exposed nor about the number of cases for the secondary outcomes. Therefore, our decision to include 10 controls per trauma case was made with the aim to maximise the possibility to have adequate power to study the abovementioned RQs. However, for rare exposures and low case numbers of secondary outcomes, the dataset may be underpowered for certain analyses.

All tests will be two-sided and $\mathrm{p}<0.05$ will be considered statistically significant.

\section{Analysis plan}

We plan to conduct the following analyses to address our RQs:

- RQ 1.1: Using the NTR 2015-2018 ( $\mathrm{n}=27180)$, rates will be calculated by AIS code/ISS/NISS (anatomic site and severity), age, sex and year.

- RQs 1.2 and 1.4: To examine trends of incidence, mortality and DALYs, we will use joinpoint regression (incidence: $\mathrm{n}=27180$ mortality: $\mathrm{n}=26562$ ).

- RQ 1.3: SMRs will be calculated to estimate the relative risk of death among trauma survivors versus the general population for various causes of death, using the NTR cohort of trauma survivors compared with cause-specific mortality rates obtained from Cause of Death Registry ( $\mathrm{n}=26562)$.

- RQs 2.1-2.4: Prospective NCC analyses of trauma risk according to demographic factors, occupation, comorbidity and drug prescription $(\mathrm{n} \approx 297000)$.

- RQs 3.1.1-3.1.4: Matched cohort analyses of relative risk of secondary outcomes following trauma diagnosis compared with healthy controls $(n \approx 297000)$. 
- RQs 3.2.1-3.2.4: Prospective cohort analyses among trauma survivors $(\mathrm{n}=26562)$ to examine whether posttrauma treatment/rehabilitation is associated, and possibly causally related with outcomes such as risk of drug use, mental illness, reduced work ability and death/poor survival.

\section{Project strengths and limitations}

An important strength of the NTR database is that it is based on mandatory reporting and on The Utstein template for uniform reporting of data following major trauma. ${ }^{55}$ The Utstein template was arrived at after a Delphi consensus process between the Scandinavian Networking Group for Trauma and Emergency Management, the UK Trauma Audit and Research Network, the German Society of Trauma Surgery and the Italian National Registry of Major Injuries, and formed the basis for the European Core Dataset 'EuroCoreD' to facilitate the establishment of a future European Trauma Registry.

A major strength of the IPOT project, which is unique in comparison to other register-based trauma projects, is the possibility to link multiple data sources by use of the PIN. This enables the establishment of a comprehensive research database with independently and prospectively collected data and complete control of loss to follow-up. The wide range of data sources that are linked gives the possibility to address both the public health burden of trauma, the causes of trauma and trauma rehabilitation and care, which is unique on a global level.

An important strength is also that all individuals with a trauma diagnosis registered in the NTR between 2015 and 2018 will be included together with 10 controls matched to each case, resulting in a large dataset of nearly 297000 individuals. Furthermore, exposure information will be collected from 2014 onwards, and thereby assure a clear prospective temporal relationship between exposure and trauma also for the first trauma cases diagnosed in 2015.

Although the comprehensive research database includes information on many possible confounding factors when evaluating the exposure-disease associations, it is still possible that confounding from unmeasured or unknown factors may arise. For example, we lack information on in-hospital drug treatment, which limits examination of drug-trauma hypotheses to prehospital and posthospital drug use. In turn, unknown in-hospital drug use may affect both posthospital drug use and the outcome (eg, mental illness and reduced work ability) in question and thereby confound such associations. Furthermore, for drug-related hypotheses 'confounding by indication' (ie, that the indication might be a shared cause for both the drug prescription and the outcome) might be particularly relevant and require adjustment for comorbidity ${ }^{56}$ Another important limitation of the project is that the 4-year time-span (1 January 2015-31 December 2018) is short and has limitations with respect to adequately addressing RQs 1.2 and 1.4, and also that the follow-up of 6 years (2015-2020) may be too short to examine typical long-term outcomes. We therefore plan future updates of the linkage with new NTR data to be able to monitor and address long-term trends of trauma. The project will not be linked to biobanks and therefore biomolecular and genetic hypotheses will not be possible to examine.

\section{PATIENT INVOLVEMENT, ETHICS AND DISSEMINATION}

The relevant patient group is represented in the project group with one representative from the Norwegian Association for Persons with Injuries and one former patient who also is a member of The Norwegian Association of Disabled. Unique patient perspectives have influenced the development of the project and the RQs. In a parallel research project based on in-depth interviews, preliminary findings show that most trauma survivors found the transition between hospital and primary healthcare system as suboptimal. These findings have been instrumental for the emphasis on post-trauma care and rehabilitation (RQs 3.1 and 3.2). Ethical approval has been obtained from the Regional Committee for Medical and Health Research Ethics (REC). REC evaluated that the benefit for society outweighed the potential harm for the individual by being included in the study and gave an exception from collecting informed consent from the nearly 297000 study participants. A data protection impact assessment has been developed in close collaboration with the data protection officer and the head of the Division of Emergencies and Critical Care at Oslo University Hospital. Moreover, according to the NTR bylaws, all patients included in the NTR are routinely contacted and informed about their right to reservation. Patients who have not reserved themselves against being registered are included in the NTR and included as subjects in research. In research papers, results will be presented on an aggregated level only, and identification of study participants will not be possible.

All results will be published in relevant peer-reviewed international scientific journals and presented at conferences, nationally and internationally. Results will also be directly communicated to the user group representatives, and to health authorities and clinicians. Important results will also be disseminated through press releases. Furthermore, lectures, the IPOT website and social media will be used to reach patients and the general public.

The proposed project is anticipated to provide new important insights into the public health burden of trauma, the aetiology of trauma and trauma survivorship, and thereby serve as an important monitoring tool for clinicians and decision makers, ultimately resulting in improved trauma prevention and trauma care.

\section{Author affiliations}

${ }^{1}$ Department of Research and Development, Division of Emergencies and Critical Care, Oslo University Hospital, Oslo, Norway

2Department of Biostatistics, Oslo Centre for Biostatistics and Epidemiology, University of Oslo, Oslo, Norway

${ }^{3}$ Department of Research, Cancer Registry of Norway, Oslo, Norway 
${ }^{4}$ The Norwegian National Trauma Registry, Division of Orthopedic Surgery, Oslo University Hospital, Oslo, Norway

${ }^{5}$ Faculty of Health Sciences, SHARE - Centre for Resilience in Healthcare, University of Stavanger, Stavanger, Norway

${ }^{6}$ Institute of Clinical Medicine, Faculty of Medicine, University of 0slo, 0slo, Norway ${ }^{7}$ Department of Circulation and Medical Imaging, Norwegian University of Science and Technology, Trondheim, Norway

${ }^{8}$ Department of Anesthesia and Intensive Care Medicine, St.Olav Hospital,

Trondheim, Norway

${ }^{9}$ Norwegian Centre for Addiction Research, Institute of Clinical Medicine, University of Oslo, Oslo, Norway

${ }^{10}$ Department of General Practice, Institute of Health and Society, University of Oslo, Oslo, Norway

${ }^{11}$ Department of Mental Disorders, Division of Mental and Physical Health, Norwegian Institute of Public Health, Oslo, Norway

${ }^{12}$ Department of Anesthesiology, Division of Emergencies and Critical Care, Oslo

University Hospital, Oslo, Norway

\section{Twitter Olav Røise @0lavroi and Leiv Arne Rosseland @r leiv}

Acknowledgements The authors thank Ronnie Babigumira, Nathalie C Støer and Bettina K Andreassen at the Cancer Registry of Norway for assistance in planning the design of this study and for preparation of the raw NTR data and sampling of controls.

Contributors LAR and OR: conceived the study. JSS and LAR: designed the study. LAR and JSS: responsible for data acquisition. JSS drafted the manuscript, and LAR, OR, TN, TC, BN, SOS, TE, TK and JMG reviewed and revised it critically for important intellectual content, and approved the final version for submission. LAR is the project principal investigator and the guarantor.

Funding The research project has received intramural funding by the 0slo University Hospital (grant no. N/A) and has been granted funding for a postdoctoral scholarship by the South-Eastern Norway Regional Health Authority (grant no. 2021043).

Competing interests None declared.

Patient consent for publication Not required.

Provenance and peer review Not commissioned; externally peer reviewed.

Supplemental material This content has been supplied by the author(s). It has not been vetted by BMJ Publishing Group Limited (BMJ) and may not have been peer-reviewed. Any opinions or recommendations discussed are solely those of the author(s) and are not endorsed by BMJ. BMJ disclaims all liability and responsibility arising from any reliance placed on the content. Where the content includes any translated material, BMJ does not warrant the accuracy and reliability of the translations (including but not limited to local regulations, clinical guidelines, terminology, drug names and drug dosages), and is not responsible for any error and/or omissions arising from translation and adaptation or otherwise.

Open access This is an open access article distributed in accordance with the Creative Commons Attribution Non Commercial (CC BY-NC 4.0) license, which permits others to distribute, remix, adapt, build upon this work non-commercially, and license their derivative works on different terms, provided the original work is properly cited, appropriate credit is given, any changes made indicated, and the use is non-commercial. See: http://creativecommons.org/licenses/by-nc/4.0/.

ORCID iDs

Jo Steinson Stenehjem http://orcid.org/0000-0002-1964-5410

Olav Røise http://orcid.org/0000-0003-4931-7001

Torsten Eken http://orcid.org/0000-0002-5943-4538

\section{REFERENCES}

1 James SL, Abate D, Abate $\mathrm{KH}$, et al. Global, regional, and national incidence, prevalence, and years lived with disability for 354 diseases and injuries for 195 countries and territories, 1990-2017: a systematic analysis for the global burden of disease study 2017. Lancet 2018;392:1789-858.

2 Tainio M, Olkowicz D, Teresiński G, et al. Severity of injuries in different modes of transport, expressed with disability-adjusted life years (DALYs). BMC Public Health 2014;14:765.

3 Murray CJ. Quantifying the burden of disease: the technical basis for disability-adjusted life years. Bull World Health Organ 1994;72:429.
4 GBD 2013 DALYs and HALE Collaborators, Murray CJL, Barber $\mathrm{RM}$, et al. Global, regional, and national disability-adjusted life years (DALYs) for 306 diseases and injuries and healthy life expectancy (HALE) for 188 countries, 1990-2013: quantifying the epidemiological transition. Lancet 2015;386:2145-91.

5 Chen HY, Ivers RQ, Martiniuk ALC, et al. Socioeconomic status and risk of car crash injury, independent of place of residence and driving exposure: results from the drive study. J Epidemiol Community Health 2010;64:998-1003.

6 d'Errico A, Punnett L, Cifuentes M, et al. Hospital injury rates in relation to socioeconomic status and working conditions. Occup Environ Med 2007;64:325-33.

7 Kristensen P, Kristiansen T, Rehn M, et al. Social inequalities in road traffic deaths at age 16-20 years among all 611,654 Norwegians born between 1967 and 1976: a multilevel analysis. Inj Prev 2012;18:3-9.

8 Driscoll TR, Ansari G, Harrison JE, et al. Traumatic work related fatalities in commercial fishermen in Australia. Occup Environ Med 1994;51:612-6.

9 Gray SE, Collie A. The nature and burden of occupational injury among first responder occupations: a retrospective cohort study in Australian workers. Injury 2017;48:2470-7.

10 Mitchell RJ, Driscoll TR, Harrison JE. Traumatic work-related fatalities involving mining in Australia. Saf Sci 1998;29:107-23.

11 Roberts SE, Marlow PB. Traumatic work related mortality among seafarers employed in British merchant shipping, 1976-2002. Occup Environ Med 2005;62:172.

12 Kennedy RL, Henry J, Chapman AJ, et al. Accidents in patients with insulin-treated diabetes: increased risk of Low-Impact falls but not motor vehicle Crashes-A prospective register-based study. J Trauma 2002;52:660-6.

13 Kessler RC, Berglund PA, Coulouvrat C, et al. Insomnia, comorbidity, and risk of injury among insured Americans: results from the America insomnia survey. Sleep 2012;35:825-34.

14 Merrill RM, Lyon JL, Baker RK, et al. Attention deficit hyperactivity disorder and increased risk of injury. Adv Med Sci 2009;54:20.

15 Bachs LC, Engeland A, Mørland JG, et al. The risk of motor vehicle accidents involving drivers with prescriptions for codeine or tramadol. Clin Pharmacol Ther 2009;85:596-9.

16 Chihuri S, Li G. Use of prescription opioids and motor vehicle crashes: a meta analysis. Accid Anal Prev 2017;109:123-31.

17 Degenhardt L, Hall W. Extent of illicit drug use and dependence, and their contribution to the global burden of disease. Lancet 2012;379:55-70.

18 Engeland A, Skurtveit S, Mørland J. Risk of road traffic accidents associated with the prescription of drugs: a registry-based cohort study. Ann Epidemiol 2007;17:597-602.

19 Haider AH, Weygandt PL, Bentley JM, et al. Disparities in trauma care and outcomes in the United States: a systematic review and meta-analysis. J Trauma Acute Care Surg 2013;74:1195-205.

20 Helmerhorst GTT, Vranceanu A-M, Vrahas M, et al. Risk factors for continued opioid use one to two months after surgery for musculoskeletal trauma. J Bone Joint Surg Am 2014;96:495-9.

21 Hogan M-E, Taddio A, Katz J, et al. Incremental health care costs for chronic pain in Ontario, Canada: a population-based matched cohor study of adolescents and adults using administrative data. Pain 2016;157:1626-33

22 Lockey D, Davies G, Coats T. Survival of trauma patients who have prehospital tracheal intubation without anaesthesia or muscle relaxants: observational study. BMJ 2001;323:141.

23 Skaga NO, Eken T, Søvik S. Validating performance of TRISS, TARN and NORMIT survival prediction models in a Norwegian trauma population. Acta Anaesthesiol Scand 2018;62:253-66.

24 Skurtveit S, Hjellvik V, Sakshaug S, et al. Forskrivning AV opioide på blå resept mot langvarige smerter. Tidsskrift for Den norske legeforening 2020.

25 Suominen P, Baillie C, Kivioja A, et al. Prehospital care and survival of pediatric patients with blunt trauma. J Pediatr Surg 1998;33:1388-92.

26 Uleberg O, Pape K, Kristiansen T, et al. Population-based analysis of the impact of trauma on longer-term functional outcomes. Br J Surg 2019;106:65-73.

27 Okie S. A flood of opioids, a rising tide of deaths. N Engl J Med Overseas Ed 2010;363:1981-5.

28 Ray WA, Chung CP, Murray KT, et al. Prescription of long-acting opioids and mortality in patients with chronic noncancer pain. JAMA 2016;315:2415-23.

29 Fredheim OMS, Skurtveit S, Breivik H, et al. Increasing use of opioids from 2004 to 2007 - pharmacoepidemiological data from a complete national prescription database in Norway. Eur J Pain 2010;14:289-94. 
30 Skurtveit S, Furu K, Borchgrevink P, et al. To what extent does a cohort of new users of weak opioids develop persistent or probable problematic opioid use? Pain 2011;152:1555-61.

31 Skurtveit SO, Sakshaug S, Hjellvik V. Bruk av vanedannende legemidler i Norge 2005 - 2013 [Use of addictive drugs in Norway 2005 - 2013]. Report in Norwegian. Folkehelseinstituttet: Folkehelseinstituttet 2014.

32 Volkow ND, McLellan AT. Opioid abuse in chronic pain misconceptions and mitigation strategies. N Engl J Med Overseas Ed 2016;374:1253-63.

33 Dai W, Liu A, Kaminga AC, et al. Prevalence of acute stress disorder among road traffic accident survivors: a meta-analysis. BMC Psychiatry 2018;18:188.

34 Collie A, Simpson PM, Cameron PA, et al. Patterns and predictors of return to work after major trauma: a prospective, population-based registry study. Ann Surg 2019;269:972-8.

35 Gabbe BJ, Simpson PM, Harrison JE, et al. Return to work and functional outcomes after major trauma. Ann Surg 2016;263:623-32.

36 Soberg HL, Bautz-Holter E, Finset A, et al. Physical and mental health 10 years after multiple trauma: a prospective cohort study. J Trauma Acute Care Surg 2015;78:628-33.

37 Soberg HL, Finset A, Bautz-Holter E, et al. Return to work after severe multiple injuries: a multidimensional approach on status 1 and 2 years postinjury. J Trauma 2007;62:471-81.

38 Overgaard M, Høyer CB, Christensen EF. Long-term survival and health-related quality of life 6 to 9 years after trauma. J Trauma 2011;71:435-41.

39 Soberg HL, Bautz-Holter E, Roise O, et al. Long-term multidimensional functional consequences of severe multiple injuries two years after trauma: a prospective longitudinal cohort study. J Trauma 2007:62:461-70.

40 The-Regional-Health-Authorities-Norway. Organisering av behandlingen av alvorlig skadde pasienter - Traumesystem OOrganization of the treatment of severly injured patients traumasystem]. Report in Norwegian. Oslo: The-Regional-HealthAuthorities-Norway, 2009.

41 Rotondo M, Cribari C, Smith R. American College of surgeons, Committee on trauma. resources for optimal care of the injured patient Chicago 2014.

42 Dahlhaug M, Roise O. Nasjonalt traumeregister årsrapport for 2019 med plan for forbedringstiltak [The national trauma registry annual report 2019]. Report in Norwegian. Oslo: Oslo University Hospital, 2020.

43 Association-for-the-Advancement-of-Automotive-Medicine. The abbreviated injury scale 2005 revision - update 2008. Des Plains, IL: Association for the Advancement of Automotive Medicine, 2008.

44 ASA-House-of-Delegates/Executive-Committee. Asa physical status classification system 2019. Available: https://www.asahq.org/ standards-and-guidelines/asa-physical-status-classification-system [Accessed 6 Nov 2020].

45 Nilssen $\mathrm{Y}$, Strand T-E, Wiik R, et al. Utilizing national patient-register data to control for comorbidity in prognostic studies. Clin Epidemiol 2014;6:395.

46 Furu K. Establishment of the nationwide Norwegian Prescription Database (NorPD)-new opportunities for research in pharmacoepidemiology in Norway. Norsk Epidemiologi 2008;18.

47 Pearce N. What does the odds ratio estimate in a case-control study? Int J Epidemiol 1993;22:1189-92.

48 Cummings P, McKnight B, Greenland S. Matched cohort methods for injury research. Epidemiol Rev 2003;25:43-50.

49 Ahmad OB, Boschi-Pinto C, Lopez AD. Age standardization of rates: a new WHO standard. Geneva: World Health Organization, 2001.

$50 \mathrm{Kim} \mathrm{HJ}$, Fay MP, Feuer EJ, et al. Permutation tests for joinpoint regression with applications to cancer rates. Stat Med 2000;19:335-51.

51 Begg S, Tomijima N, Vos T, et al. Global burden of injury in the year 2000: an overview of methods. Citeseer, 2003.

52 Charlson ME, Pompei P, Ales KL, et al. A new method of classifying prognostic comorbidity in longitudinal studies: development and validation. J Chronic Dis 1987;40:373-83.

53 Beyersmann J, Wolkewitz M, Allignol A, et al. Application of multistate models in hospital epidemiology: advances and challenges. Biom J 2011;53:332-50.

54 Hernán MA, Robins JM. Causal inference: what if. Boca Raton: Chapman \& Hill/CRC, 2020.

55 Ringdal KG, Coats TJ, Lefering R, et al. The Utstein template for uniform reporting of data following major trauma: a joint revision by SCANTEM, TARN, DGU-TR and RITG. Scand J Trauma Resusc Emerg Med 2008;16:7.

56 Kyriacou DN, Lewis RJ. Confounding by indication in clinical research. JAMA 2016;316:1818-9. 